\title{
INFLUENCE OF LIQUEFIED AND CCB CONTAINING LIQUEFIED WOOD ON GROWTH OF WOOD DECAY FUNGI
}

\author{
D. Hrastnik ${ }^{1, \star}$, F. Budija ${ }^{1}$, M. Humar ${ }^{1}$, M. Petric ${ }^{1}$
}

\begin{abstract}
There are high amounts of post-consumed protected waste wood removed from service every year. The residual biocides, including copper, chromium and boron from $\mathrm{CCB}(\mathrm{Cu}, \mathrm{Cr}, \mathrm{B})$ in post-consumed wood that was protected with biocides may cause environmental problems during waste management, for example during land filling. Therefore, the aim of this study was to find out if $\mathrm{Cu}$ and $\mathrm{Cr}$ in the processed waste wood, previously treated with $\mathrm{CCB}$, can be re-used as a wood preservative or in coatings made of liquefied wood. Liquefaction of CCB containing waste wood could be as well the first step in the elimination process of metals. So, the optimal conditions for liquefaction of $\mathrm{CCB}(\mathrm{Cu}, \mathrm{Cr}$ and B) containing black poplar (Populus nigra L.) wood were established and compared with liquefaction of uncontaminated black poplar wood. The reactants for liquefaction of black poplar wood sawdust were ethylene glycol (EG) and sulphuric acid. It was observed that in the last stages of the liquefaction process, the presence of $\mathrm{Cu}, \mathrm{Cr}$ and $\mathrm{B}$ did not have any influence on liquefaction yield (LY), while their influence was observed in first stages of the solvolytic reaction. Investigations of fungicidal properties of uncontaminated and CCB containing liquefied wood showed higher antifungal efficacy of liquefied wood without $\mathrm{Cu}, \mathrm{Cr}$ and $\mathrm{B}$ than of liquefied wood that contained $\mathrm{CCB}$. In the tested concentration range, the presence of $\mathrm{Cu}$ even promoted the growth of selected wood decay fungi. One of the reasons for higher toxicity of liquefied black poplar sawdust without $\mathrm{Cu}, \mathrm{Cr}$ and $\mathrm{B}$, was its very low $\mathrm{pH}$ value.
\end{abstract}

Keywords: Liquefied wood, copper, chromium, boron, preservatives, post-consumed wood, wood decay fungi

\section{INTRODUCTION}

Due to a threat of shortage of fossil based sources and especially due to negative impacts of their usage on the environment, utilisation of renewable natural resources, including biomass, is becoming more and more important. Biomass is the term used to describe all biologically produced matter. Biomass, mainly in the form of wood, is the oldest form of energy used by humans. Beside its applications in a natural - solid form, liquid and gas biomass based products can be produced and used as a fuel or for further organic syntheses (Lin et al. 1997).

The conversion technologies into a liquid or gas state can be separated into four basic categories: direct combustion processes, biochemical, thermochemical and agrochemical processes (Demirbas 2001). The most important ones are biochemical and thermochemical processes (Tsoul et al. 2004). Biochemical processes are anaerobic digestion (decomposition through bacterial action in the absence of oxygen) and alcoholic fermentation (ethanol can be produced from certain materials which contain sugars, starch, hemicellulose or cellulose). Further categories of thermochemical processes are pyrolysis, gasification, supercritical fluid extraction, hydro thermal upgrading process and liquefaction. Pyrolysis converts biomass into a liquid, charcoal and non-condensable gases, acetic acid, acetone and methanol, by heating the biomass to about $480^{\circ} \mathrm{C}$ in the absence of air. Gasification is similar to pyrolysis but it is 
performed at higher temperatures in order to optimize the gas production. Application of supercritical fluid extraction enables biomass to be converted to primary products and thereafter further on into a variety of final products. A hydro thermal upgrading process is another way to produce bio-crudes with converting biomass in a wet environment at high pressure to partially oxygenated hydrocarbons. Liquefaction is performed at relatively low temperatures and high pressure using a catalyst (Demirbas 2001). However, with a correctly selected solvent system and a catalyst, the biomass can be liquefied also under atmospheric pressure at a moderately elevated temperature $\left(150^{\circ} \mathrm{C}\right)$. There have been numerous reports in the literature on wood liquefaction and possible applications of liquefied wood (for instance in Shiraishi and Yoshioka 1998, Kobayashi et al. 2000, Kurimoto et al. 2001, Yamada and Ono 2001, Doh et. al. 2005, Budija et al. 2009, Kunaver et al. 2010). As a source for liquefaction, biocide treated post-consumed wood can be used as well as shown for instance by Shiraishi and Hse (2000) or Lin and Hse (2005). Namely, impregnated post-consumed wood still contains the biocides which were chosen due to their toxicity towards wood decay organisms, but are also toxic to other organisms and thusly potentially harmful to humans and to the environment (Krook et al. 2006, Ochoa-Acuña and Roberts 2006). Several methods for the disposal of biocide containing post-consumed wood have been studied. These are: recycling and recovery, chemical extraction, bioremediation, electrodialytic remediation and thermal destruction (Helsen and Van den Bulck 2005). The intention of all these methods is to remove toxic preservatives out of wood without harmful emissions into the environment. As mentioned, that is why some investigations were focused on liquefaction of biocide containing post-consumed wood. Additionally, ideas to use liquefied post-consumed wood with toxic preservatives for wood preservation have emerged. Humar et al. (2011) liquefied CCB (copper, chromium and boron compounds based wood preservative formulation) containing Norway spruce wood and tried to use it as a preservative for common beech and Norway spruce wood. However, the results did not clearly show if the CCB containing liquefied wood had biocidal properties or was bio-inactive. On the other hand, leaching of copper from spruce wood, impregnated with the liquefied CCB treated wood was significantly reduced.

The aim of this study was continuation of investigations of Humar et al. (2011) in order to optimise liquefaction of CCB containing wood with ethylene glycol (EG). We also wanted to clarify possible fungicidal properties of liquefied and of $\mathrm{CCB}$ containing liquefied wood, especially as the liquefied wood proved to be an effective binder for boron based preservative compounds (Lesar et al. 2012). To simplify the experiments, sawdust of black poplar wood was treated with commercial CCB formulations and afterwards liquefied, instead of Norway spruce wood that was used in our previous research (Humar et al. 2011). We believe, that as a model, black poplar wood is more convenient than Norway spruce, as liquefaction of black poplar wood is rather unproblematic.

\section{MATERIAL AND METHODS}

In order to avoid uncontrolled influence of weathering, biological degradation and to have defined material, this research was not performed with the aged impregnated wood. So, instead of using the real samples from service, our experiments were performed with the model specimens - CCB impregnated sawdust. Black poplar (Populus nigra L.) wood was used for liquefaction. Sawdust was prepared using the Retsch SM 2000 laboratory cutting mill and fractionated using a $0.24 \mathrm{~mm}$ sieve. The sawdust was divided into three parts. The first part was not contaminated with CCB (uncontaminated black poplar sawdust - UBP sawdust). Into the sawdust of the second part, the commercial preservative CCB solution, prepared from $34.0 \% \mathrm{CuSO}_{4} \times 5 \mathrm{H}_{2} \mathrm{O}, 37.3 \% \mathrm{~K}_{2} \mathrm{Cr}_{2} \mathrm{O}_{7}$ and $28.7 \% \mathrm{H}_{3} \mathrm{BO}_{3}$ (Silvanol, Silvaprodukt, Ljubljana, Slovenia) was added, to reach low concentration of the biocide (target retention $4 \mathrm{~kg} / \mathrm{m}^{3}$, as used in use class 3 applications) in wood (low retention impregnated black poplar sawdust - LRIBP sawdust). The third part contained higher concentration (target retention $16 \mathrm{~kg} / \mathrm{m}^{3}$, as used in use class 4 applications) of the biocide (high retention impregnated black poplar sawdust - HRIBP sawdust). Black poplar sawdust was impregnated with the CCB formulation as follows: it was soaked in the 
aqueous solution of CCB for three days in order to achieve uniform distribution and sufficient retention. The immersed sawdust was mixed two times per day. As wet sawdust is heavier than water, it sank, so there was no loading necessary. This process enabled uniform distribution of the active ingredients in the wood. As cross-sections of the sawdust particles are rather small, the volume of the particles was uniformly impregnated. Thus the material was more homogenous than the ground impregnated timber would be. Afterwards, the impregnated wood was oven dried at $60^{\circ} \mathrm{C}$ for 7 days and furthermore conditioned at laboratory conditions for 14 days to ensure complete reduction of chromium from $\mathrm{Cr}(\mathrm{VI})$ to $\mathrm{Cr}(\mathrm{III})$. Concentrations of copper and chromium in the UBP, LRIBP and HRIBP sawdust, and in the nutrient medium with the highest added amount of HRIBP were determined with the X-ray fluorescence spectrometer (Oxford instruments, Twin-x). The measurements were performed with the PIN detector $(U=26 \mathrm{kV}, I=112 \mu \mathrm{A}, t=360 \mathrm{~s})$ on two parallel specimens.

Prior to liquefaction, the UBP, LRIBP and HRIBP sawdust was oven dried $\left(24 \mathrm{~h}, 103^{\circ} \mathrm{C}\right)$. The liquefaction reaction mixtures were prepared with $4 \mathrm{~g}$ of sawdust. Different ratios of ethylene glycol (EG) as a reagent and sulphuric acid $\left(\mathrm{H}_{2} \mathrm{SO}_{4}\right)$ as a catalyst were used. The ratios between sawdust and EG were $1: 3,1: 4$ and $1: 5$. Portions of the added sulphuric acid were 2,3 and $4 \%$ to the weight of EG. The reaction times were 8, 15, 30, 45, 60, 75, 90, 105 and $120 \mathrm{~min}$. Different concentrations of EG and the catalyst was applied to study their influence on liquefaction yield (LY). The liquefaction reactions were carried out in thin-walled test tubes which were immersed in oil bath preheated to $150^{\circ} \mathrm{C}$ to start the reaction. After the selected reaction time the test tubes were immersed in cool tap water to quench the reaction. The obtained products were then diluted with a mixture of 1,4-dioxane and water (4/1) and filtered through filter disks (Sartorius filter disks 388 grade $/ 84 / \mathrm{mm}^{2}$ ). Afterwards, the mixture of water and 1,4-dioxane was evaporated under reduced pressure obtained with a water pump. Concentrations of copper and chromium in UBP, LRIBP and HRIBP liquefied sawdust were determined with X-ray fluorescence spectroscopy, similarly as already described for the concentrations in impregnated sawdust prior to liquefaction.

Liquefaction parameters used for investigations of fungicidal properties of UBP, LRIBP and HRIBP liquefied sawdust were temperature $150^{\circ} \mathrm{C}$, ratio between sawdust and $\mathrm{EG} 1: 3$ and $3 \%$ of added sulphuric acid to the weight of EG. Fungicidal properties of UBP, LRIBP and HRIBP liquefied sawdust were examined with brown and white rot fungi. The brown rot fungi were Gloeophyllum trabeum (Pers.) Murrill, and Antrodia vaillantii (DC.) Ryvarden. The white rot fungus was Trametes versicolor (L.:Fr.) Quél. The fungal cultures were grown and maintained on potato dextrose agar (PDA - DIFCO Laboratories, USA). $39 \mathrm{~g}$ of PDA was added into $1 \mathrm{~L}$ of distilled water. $20 \mathrm{~mL}$ of liquid PDA was added into test tubes which were closed with aluminium foil. The test tubes were held in an autoclave for 15 $\min \left(121^{\circ} \mathrm{C} ; 1,5\right.$ bar $)$. After that they were brought into a laminar flow where UBP, LRIBP and HRIBP liquefied sawdust was added $(100,200,500$ or $1000 \mu \mathrm{L})$ into still hot and liquid PDA, to achieve uniform distribution. It was not possible to add higher amounts of the liquefied sawdust containing $\mathrm{Cu}, \mathrm{Cr}$ and $\mathrm{B}$ because PDA cannot harden when containing too high concentrations of the mentioned elements from the biocide. In addition, it was expected, that the synergism between biocides and liquefied wood could be maybe expressed also at lower concentrations. Still hot and liquid mixtures were spilled into Petri dishes (sterile, plastic, $9 \mathrm{~cm}$ diameter) where they were cooled to room temperature. Three parallel samples per each combination were prepared for each fungi. To perform the growth test, three additional Petri dishes for each fungi with pure PDA, without liquefied sawdust, were prepared. The Petri dishes were inoculated with small pieces of fungal mycelia and exposed for 13 days at constant laboratory conditions $\left(T=25^{\circ} \mathrm{C}, R H=75 \%\right)$. The cumulative growth was measured from the third day of inoculation. The measurements of fungal growth in three directions gave us the average fungal mycelia growth per day. Fungi on pure PDA overgrew Petri dishes in 10 days, and this is why fungal growth reduction was observed on the $10^{\text {th }}$ day. Nevertheless, some other interesting results were exhibited also during all 13 days of exposing to fungi. 


\section{RESULTS AND DISCUSSION}

\section{Liquefaction of CCB containing black poplar wood}

Concentrations of copper and chromium in UBP, LRIBP and HRIBP sawdust are shown in table 1. Both elements in UBP sawdust were under detection limit of the X-ray fluorescence spectrometer. The concentrations of copper and chromium in LRIBP and HRIBP sawdust are in compliance with the target retention of $4 \mathrm{~kg}$ of CCB per $1 \mathrm{~m}^{3}$ as used in use class 3 applications and $16 \mathrm{~kg}$ of CCB per $1 \mathrm{~m}^{3}$ as used in use class 4 applications.

Table 1. Concentration of copper and chromium in UBP, LRIBP and HRIBP sawdust

\begin{tabular}{l|cc} 
& $\mathrm{Cu}$ & $\mathrm{Cr}$ \\
\hline $\begin{array}{l}\text { Uncontaminated black poplar sawdust } \\
\text { (UBP sawdust) }\end{array}$ & $0^{*}$ & $0^{*}$ \\
$\begin{array}{l}\text { Low retention impregnated black poplar } \\
\text { sawdust (LRIBP sawdust) }\end{array}$ & $1455 \mathrm{ppm}$ & $2725 \mathrm{ppm}$ \\
$\begin{array}{l}\text { High retention impregnated black poplar } \\
\text { sawdust (HRIBP sawdust) }\end{array}$ & $3314 \mathrm{ppm}$ & $6319 \mathrm{ppm}$ \\
\hline
\end{tabular}

* under the detection limit of $3 \mathrm{ppm}$ for $\mathrm{Cu}$ and of $4 \mathrm{ppm}$ for $\mathrm{Cr}$.

Determination of the optimal liquefaction conditions of uncontaminated black poplar sawdust was studied by Budija et al. (2009). They used diethylene glycol (DEG) as a reagent and sulphuric acid as a catalyst. The study showed that almost $100 \%$ of sawdust was liquefied if the ratio between sawdust and DEG was higher than 1:2. Further increasing of the ratio did not have influence on LY. Our study with EG showed similar results at liquefaction of LRIBP sawdust, where EG was used as a reagent and sulphuric acid as a catalyst. In order to determine the optimal liquefaction conditions, three different ratios between EG and LRIBP sawdust were tested $(1: 3 ; 1: 4 ; 1: 5)$, at the fixed concentration of the catalyst to the weight of EG $(3 \%)$ and at a constant temperature $\left(150^{\circ} \mathrm{C}\right)$ as shown in figure 1.

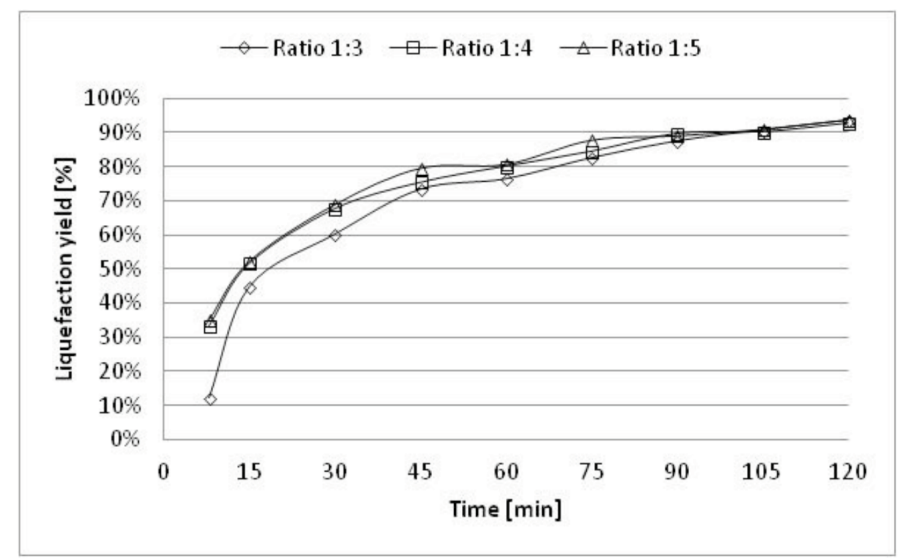

Figure 1. Liquefaction yield (LY) at the constant concentration of the catalyst to the weight of EG $(3 \%)$ and temperature $\left(150^{\circ} \mathrm{C}\right)$, dependent on different ratios between EG and LRIBP sawdust. 
Differences in LY were observable only in the first stages of liquefaction, where a higher amount of EG was needed to achieve uniform mixing of EG with the sawdust. The same was observed by Budija et al. (2009). In the last stage of liquefaction, the influence of the ratio between EG and LRIBP sawdust was not exhibited anymore, as the sawdust was immersed long enough to be completely wetted and presumably impregnated with the reaction mixture. Because of lower LY in the first stages of liquefaction reaction where the ratio between EG and LRIBP sawdust was $1: 3$ and no differences in LY in dependence of the EG to LRIBP sawdust ratio in the last stage of the liquefaction reaction, the influence of the concentration of the catalyst on LY was studied only at the EG to LRIBP sawdust ratio of $1: 4$, at $150^{\circ} \mathrm{C}$ (Figure 2).

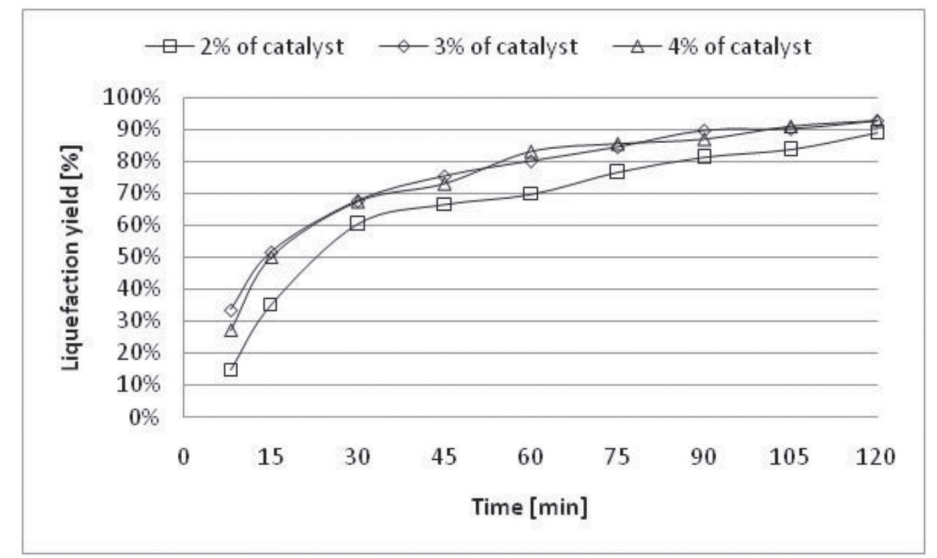

Figure 2. Liquefaction yield (LY) at the constant ratio between EG and LRIBP sawdust of 1 : 4 at $150^{\circ} \mathrm{C}$ in dependence of the catalyst concentration.

As can be seen from figure 2, more than $2 \%$ of the catalyst according to the weight of EG was needed to achieve good LY but on the other hand, further increase of the concentration above 3\% did not influence the LY any more.

To check a potential influence of the biocide content in poplar wood on LY, UBP, LRIBP and HRIBP sawdust were liquefied at the following conditions: the ratio between EG and sawdust was 1:3, the catalyst concentration was $3 \%$ according to the weight of $\mathrm{EG}$ and the temperature $150^{\circ} \mathrm{C}$ (Figure 3). There were significant differences observed in the initial stages of the liquefaction reaction. The reason for the lower LY at the HRIBP sawdust at the beginning of liquefaction process could be in rather poor wetting of CCB impregnated wood by EG. Namely, it is well known, that CCB impregnated wood is less hydrophilic than uncontaminated wood (Maldas and Kamdem 1998). This was clearly evident at our experiment as well. Because of acidity of $\mathrm{CCB}$ ( $\mathrm{pH}$ value of commercial CCB formulations is around 3 (Humar et al. 2005) we expected better LY at HRIBP sawdust but the results were not in agreement with our expectations. In addition, it was presumed that the presence of metal ions in the system will catalyse the process, but as can be resolved from Figure 3, increased concentrations of copper and chromium did not result in increased LY. 


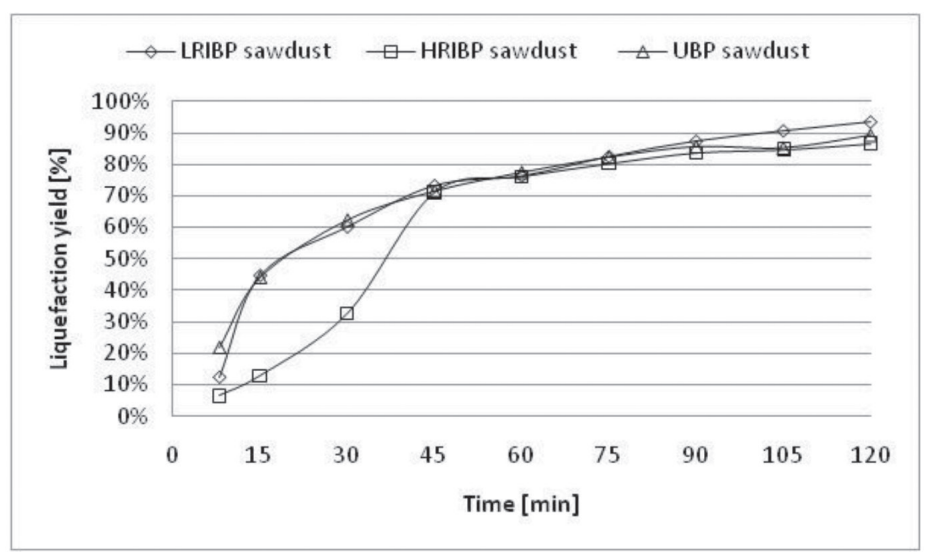

Figure 3. Liquefaction yield (LY) at the EG : sawdust ratio of $1: 3,3 \%$ of the catalyst to the weight of $\mathrm{EG}$ and at $150^{\circ} \mathrm{C}$ in dependence of the sawdust type.

Concentrations of copper and chromium in UBP, LRIBP and HRIBP liquefied sawdust are shown in table 2. In comparison with the data in table 1, the concentrations of copper and chromium in LRIBP and HRIBP liquefied sawdust were substantially lower than in CCB containing wood prior to liquefaction. There was $80 \%$ and $60 \%$ less copper and chromium in the liquefied sawdust, respectively. The most important reason is the dilution during the liquefaction process, since the ratio between sawdust and EG was 1: 3. Secondly, liquefaction yields of up to approximately $90 \%$ were achieved and some copper and chromium could remain in the solid residues. Additionally, during liquefaction some volatile products that evaporate from the mixture during liquefaction are formed (Budija et al. 2010). It is known that copper and chromium atoms/ions can form some volatile complexes with organic compounds and these could evaporate from the liquefaction mixture (Shapcott et al. 1977, Helsen et al. 2007). Formation of such compounds cannot be excluded also in our case. Elucidation of the mass balance of the heavy metals should be the topic of future investigations.

Table 2. Concentration of copper and chromium in UBP, LRIBP and HRIBP liquefied sawdust.

\begin{tabular}{l|cc} 
& $\mathrm{Cu}$ & $\mathrm{Cr}$ \\
\hline $\begin{array}{l}\text { Uncontaminated black poplar } \\
\text { liquefied sawdust (UBP liquefied } \\
\text { sawdust) }\end{array}$ & $0 * \mathrm{ppm}$ & $0 * \mathrm{ppm}$ \\
$\begin{array}{l}\text { Low retention impregnated black } \\
\text { poplar liquefied sawdust (LRIBP }\end{array}$ & $272 \mathrm{ppm}$ & $1050 \mathrm{ppm}$ \\
$\begin{array}{l}\text { liquefied sawdust) } \\
\begin{array}{l}\text { High retention impregnated black } \\
\text { poplar liquefied sawdust (HRIBP } \\
\text { liquefied sawdust) }\end{array}\end{array}$ & $458 \mathrm{ppm}$ & $2405 \mathrm{ppm}$ \\
\hline \multicolumn{1}{c}{$*$ under the detection limit of $3 \mathrm{ppm}$ for $\mathrm{Cu}$ and of $4 \mathrm{ppm}$ for $\mathrm{Cr}}$.
\end{tabular}

Although the main focus of the present article is on $\mathrm{Cu}$ and $\mathrm{Cr}$ in liquefied wood, one may be interested in what happens with the boron containing compounds during liquefaction of CCB containing sawdust and could they also have any role in a potential fungal inhibition. On the basis of the data from literature, three assumptions can be made: (i) volatile complexes of boron with wood polymer fragments and other compounds in liquefied wood could be formed. Because of the high temperature applied during the liquefaction reaction, the majority of boron could evaporate from the mixture; (ii) various complexes 
with organic compounds in liquefied wood could be formed; (iii) some part of boron could be eliminated by evaporation of volatile complexes and the other part could remain in the liquefaction product in the form of stable complexes. For instance, some borate esters (which could certainly be formed with some depolymerised fragments of wood components) are well known to be volatile. Even more, such complexes are well known to be applied as wood preservatives (e.g. Baysal and Yalinkilic 2005). It is also known that dehydration of boric acid under heat yields some forms of boric oxide depending on temperature level, and on the other hand, boric acid itself can be vaporised under heat. Similarly, as written by Kataoka et al. (2008), it is well known that boric acid and its salts sodium tetraborate and sodium metaborate are all volatile. Especially in acidic media (such as liquefied wood in our experiment) the volatilities are extremely increased. Volatility of the complexes containing boron was for example also illustrated by D'Ulivo (2004). Secondly, various boron containing complexes (for the purpose of wood protection) are mentioned in the review by Obanda et al. (2008). Just as an example, spiro-borate complexes of derivatised 2-hydroxybenzyl alcohol may react with $\mathrm{Cu}$ (II) to form the tetrakis boronato bis aquo copper II. Penn et al. (1997) report on borate complexes of carbohydrates - the borate complexes with sugar hydroxyl groups. Borate is also known to form stable complexes with cis-diols (Landers et al. 1992). As stated by Asad et al. (1997) a range of substances form chelates with boron, including polyhydric alcohols, sugars, and phenolic compounds. All in all, the mentioned examples support well enough our presumptions mentioned under (i)-(iii), but certainly they should be elucidated and potentially confirmed by additional extensive research of boron complexes in liquefied wood.

\section{Fungicidal properties of liquefied sawdust}

Further on, fungicidal properties of UBP, LRIBP and HRIBP liquefied sawdust were determined. Liquefaction was carried out at $150^{\circ} \mathrm{C}$ and with $3 \%$ of added sulphuric acid. The ratio between EG and sawdust was 1: 3 . Although these were not the optimal conditions in the first stages of liquefaction (Figure 1), they were used to minimize the influence of non-reacted EG in liquefied sawdust on fungicidal properties. The higher ratio between EG and sawdust does not have the influence on LY in the last stage of liquefaction (Figure 1). The fungal cultures were grown and maintained on PDA because we wanted to draw attention just to the influence of liquefied sawdust on chosen fungi and to avoid potential interactions between wood and liquefied wood. Reduction of fungal growth due to addition of different concentrations of UBP, LRIBP and HRIBP liquefied sawdust into PDA was comparable for all 3 fungal species (Table 3). 
Table 3. Influence of different added concentrations of UBP, LRIBP and HRIBP liquefied sawdust on growth reduction of Trametes versicolor, Antrodia vaillantii and Gloeophyllum trabeum compared to fungal growth on pure PDA on the $10^{\text {th }}$ day after inoculation.

\begin{tabular}{|c|c|c|c|c|}
\hline \multirow{3}{*}{$\begin{array}{c}\text { Type of liquefied } \\
\text { wood }\end{array}$} & \multirow{3}{*}{$\begin{array}{l}\text { Volume of liquefied } \\
\text { wood per } 20 \mathrm{~mL} \text { of } \\
\text { growth medium }\end{array}$} & \multicolumn{3}{|c|}{ Wood decay fungi } \\
\hline & & $\begin{array}{l}\text { Trametes } \\
\text { versicolor }\end{array}$ & $\begin{array}{l}\text { Antrodia } \\
\text { vaillantii }\end{array}$ & $\begin{array}{c}\text { Gloeophyllum } \\
\text { trabeum }\end{array}$ \\
\hline & & \multicolumn{3}{|c|}{ Growth reduction } \\
\hline \multirow{4}{*}{$\begin{array}{l}\text { UBP liquefied } \\
\text { sawdust }\end{array}$} & $100 \mu \mathrm{L}$ & $-0,98 \%$ & - & $-3,25 \%$ \\
\hline & $200 \mu \mathrm{L}$ & $-6,83 \%$ & $-17,32 \%$ & $-20,13 \%$ \\
\hline & $500 \mu \mathrm{L}$ & $-56,59 \%$ & $-25,59 \%$ & $-67,53 \%$ \\
\hline & $1000 \mu \mathrm{L}$ & $-100,00 \%$ & $-100,00 \%$ & $-93,51 \%$ \\
\hline \multirow{4}{*}{$\begin{array}{l}\text { LRIBP liquefied } \\
\text { sawdust }\end{array}$} & $100 \mu \mathrm{L}$ & $-0,98 \%$ & $-18,50 \%$ & $-11,69 \%$ \\
\hline & $200 \mu \mathrm{L}$ & $-14,63 \%$ & $-26,77 \%$ & $-27,92 \%$ \\
\hline & $500 \mu \mathrm{L}$ & $-53,17 \%$ & - & $-61,69 \%$ \\
\hline & $1000 \mu \mathrm{L}$ & $-99,02 \%$ & $-96,06 \%$ & $-75,97 \%$ \\
\hline \multirow{4}{*}{$\begin{array}{l}\text { HRIBP liquefied } \\
\text { sawdust }\end{array}$} & $100 \mu \mathrm{L}$ & $-6,83 \%$ & $5,12 \%$ & $-11,69 \%$ \\
\hline & $200 \mu \mathrm{L}$ & $-7,80 \%$ & $-3,15 \%$ & $-31,82 \%$ \\
\hline & $500 \mu \mathrm{L}$ & $-48,78 \%$ & $-8,66 \%$ & $-53,25 \%$ \\
\hline & $1000 \mu \mathrm{L}$ & $-68,78 \%$ & $-44,88 \%$ & $-69,48 \%$ \\
\hline \multicolumn{2}{|r|}{ Pure PDA } & $0,00 \%$ & $0,00 \%$ & $0,00 \%$ \\
\hline
\end{tabular}

Some interesting results in table 3 are compared further and more clearly shown in figures 4-6.

Figure 4 shows that addition of $1000 \mu \mathrm{L}$ of UBP liquefied sawdust completely reduced growth of Trametes versicolor. The growth reduction after addition of $1000 \mu \mathrm{L}$ of LRIBP liquefied sawdust into PDA was lower and even less exhibited when $1000 \mu \mathrm{L}$ of HRIBP liquefied sawdust was added. 


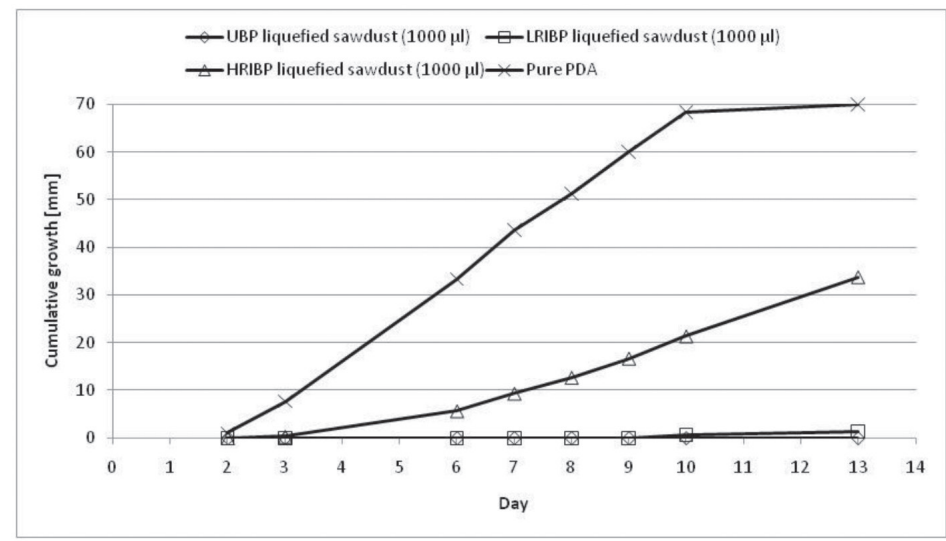

Figure 4. Influence of UBP, LRIBP and HRIBP liquefied sawdust $(1000 \mu \mathrm{L}$ was added per $20 \mathrm{~mL}$ of PDA) on growth reduction of Trametes versicolor.

The same was observed at Antrodia vaillantii (Figure 5), although the observed growth reduction was not as pronounced as at Trametes versicolor.

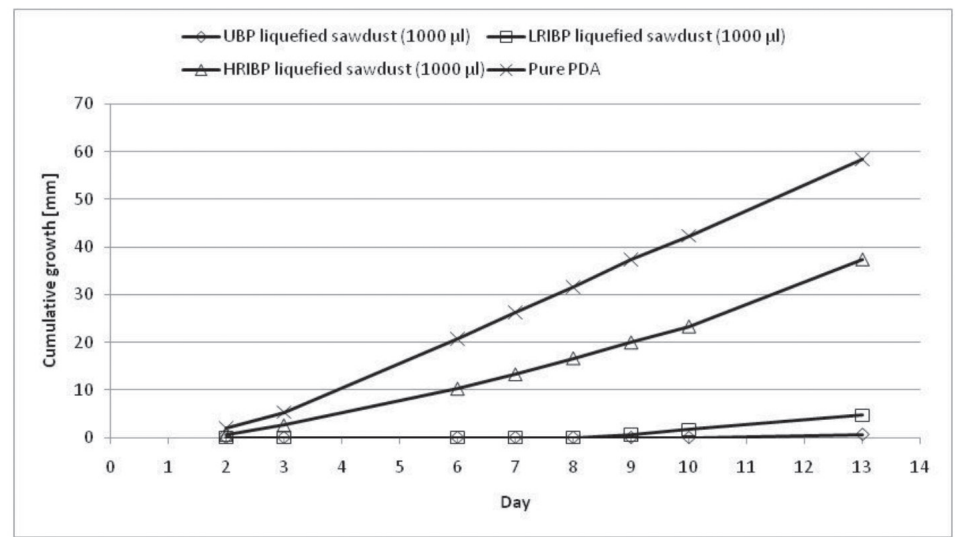

Figure 5. Influence of UBP, LRIBP and HRIBP liquefied sawdust (1000 $\mu \mathrm{L}$ was added per $20 \mathrm{~mL}$ of PDA) on growth reduction of Antrodia vaillantii.

The lowest growth reduction was observed at Gloeophyllum trabeum (Figure 6). Data in Figures 4, 5 and 6, show that the addition of LRIBP and HRIBP liquefied sawdust in general reduced the growth, but to a much lesser extent than the UBP liquefied sawdust without copper and chromium. So, it seems that copper and chromium did not reduce the growth but even promoted it, when compared to the effect of UBP liquefied sawdust containing samples. One may assume that the observed growth reduction at the LRIBP and HRIBP liquefied sawdust samples was the consequence of the liquefied sawdust itself, only, especially when its $\mathrm{pH}$ is taken into consideration. $\mathrm{pH}$ of LRIBP and HRIBP liquefied sawdust was about 0.8 , while $\mathrm{pH}$ of UBP liquefied sawdust was about 0,05 . This could be one reason why UBP liquefied sawdust was more fungitoxic than LRIBP and HRIBP. The minimum inhibitory concentration of copper for Trametes versicolor is $160 \mathrm{ppm}$ and for Gloeophyllum trabeum $640 \mathrm{ppm}$ (Humar and Lesar 2008). The minimum inhibitory concentration of copper for Antrodia vaillantii is $1600 \mathrm{ppm}$ in nutrient medium (Pohleven et al. 2001). In table 2 it is shown that the concentration of copper in LRIBP liquefied sawdust was $272 \mathrm{ppm}$ and in HRIBP liquefied sawdust $458 \mathrm{ppm}$. In the growth medium with 
the highest amount of $1000 \mu \mathrm{L}$ HRIBP liquefied sawdust the concentration of copper was only $10 \mathrm{ppm}$. This concentration of copper is much lower than the inhibitory concentration for any of our test fungi.



Figure 6. Influence of UBP, LRIBP and HRIBP liquefied sawdust (1000 $\mu \mathrm{L}$ was added per $20 \mathrm{~mL}$ of PDA) on growth reduction of Gloeophyllum trabeum.

Figures 7, 8 and 9 show the influence of UBP, LRIBP and HRIBP liquefied sawdust concentration in PDA on growth reduction of Trametes versicolor, which is the most sensitive one to copper (Humar and Lesar 2008), as indicated also by our results.

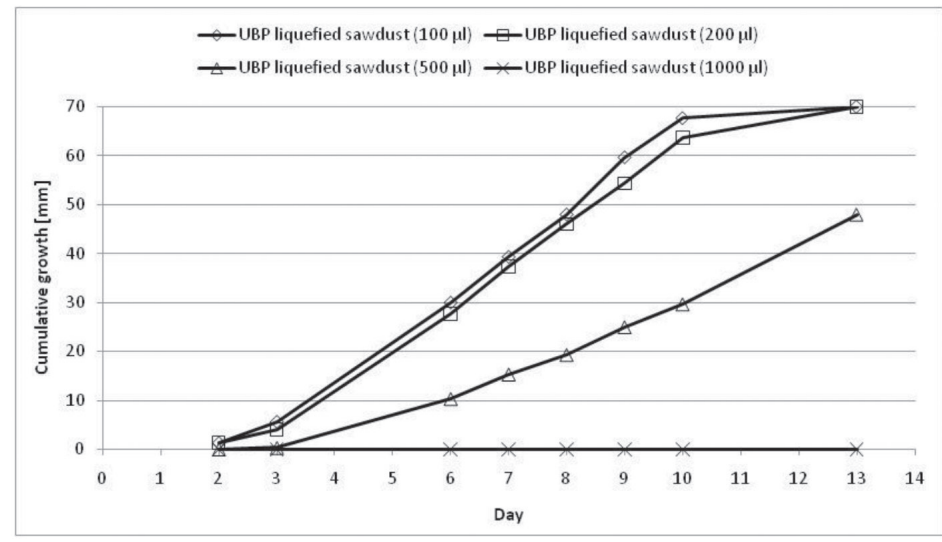

Figure 7. Influence of different concentrations of UBP liquefied sawdust on growth reduction of Trametes versicolor.

The concentration of $1000 \mu \mathrm{L}$ UBP liquefied sawdust per $20 \mathrm{~mL}$ of the growth medium (Figure 7) was high enough to inhibit the growth of Trametes versicolor. On the other hand, Humar et al. (2011) observed that the "liquefaction" reaction product of ethylene glycol and $\mathrm{H}_{2} \mathrm{SO}_{4}$, without wood, reduced decay, but not enough to fulfil the requirements of the EN 113-2004 standard

It was expected, that LRIBP liquefied sawdust containing CCB could perform better than the UBP liquefied sawdust, due to the remained biocides. But the addition of $1000 \mu \mathrm{L}$ of LRIBP liquefied sawdust was not satisfactory anymore to inhibit the growth of Trametes versicolor (Figure 8). In the last days Trametes versicolor started to grow. 


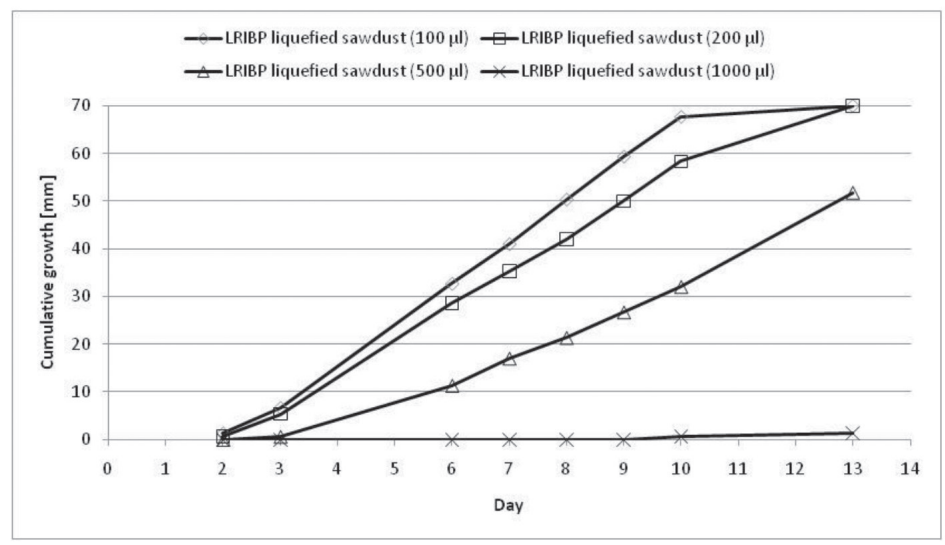

Figure 8. Influence of different concentrations of LRIBP liquefied sawdust on the growth reduction of Trametes versicolor.

Even less fungitoxic to Trametes versicolor was HRIBP liquefied sawdust (Figure 9). Various studies showed that copper is biocidally inactive in small quantities. Even more, it is an essential trace mineral for the growth of plants and is generally absorbed in the form of the divalent cation $\mathrm{Cu}^{2+}$. It is incorporated into a large number of plant organic compounds. It is also an enzyme activator and becomes a component of certain enzymes that function in respiration and photosynthesis processes. Stimulating effect of cooper on the growth of fungi was observed by Wazny and Thornton (1986).

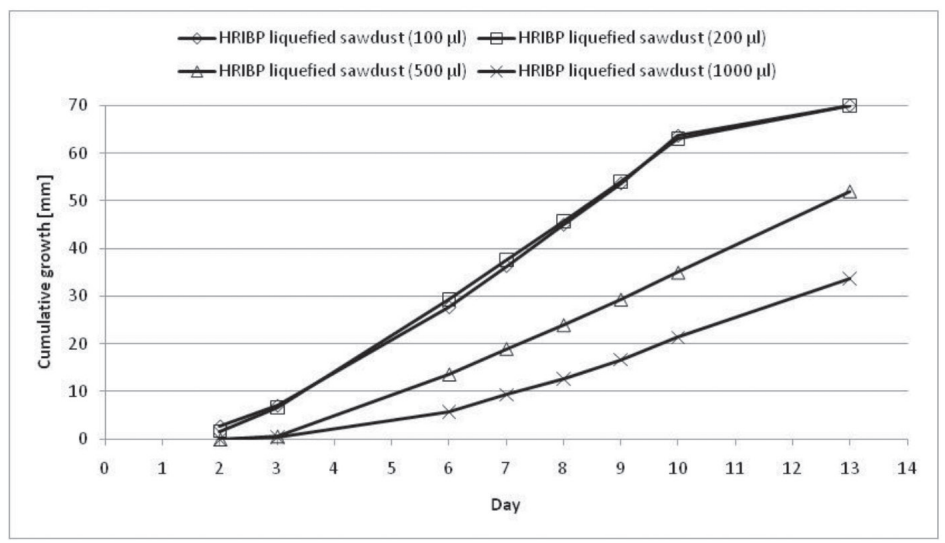

Figure 9. Influence of different concentrations of HRIBP liquefied sawdust on the growth reduction of Trametes versicolor.

Lower toxicity of LRIBP and HRIBP liquefied sawdust in comparison to the observed fungitoxic effectiveness of the liquefied sawdust without the biocide indicate that liquefied sawdust, copper and chromium did not act synergistically and that very probably new chemical complexes (compounds) with fungitoxic effectiveness were not formed in the liquefied mixtures. Tentatively, some complexes between $\mathrm{Cu}, \mathrm{Cr}$ or B and compounds in liquefied wood mixtures could be formed, but if this is the case, they are without fungitoxic effectiveness or they even lower fungicidal activity of the system. 


\section{CONCLUSIONS}

Liquefaction of $\mathrm{CCB}(\mathrm{Cu}, \mathrm{Cr}$ and $\mathrm{B})$ containing wood could be the first step in an elimination process of metals from waste, post-consumed biocidally protected wood. Therefore, we investigated the possibility of liquefaction of $\mathrm{CCB}$ containing poplar wood and it was proven that $\mathrm{CCB}(\mathrm{Cu}, \mathrm{Cr}$ and $\mathrm{B}$ ) containing wood can be liquefied just as successfully as wood without remains of a CCB wood preservative. However, the presence of the metal ions in the system did not catalyse the liquefaction process, as exhibited by the same liquefaction yields for wood with and without $\mathrm{Cu}, \mathrm{Cr}$ and $\mathrm{B}$. Optimal liquefaction conditions for $\mathrm{CCB}$ containing wood are similar to those for uncontaminated wood.

As it was shown by our previous research, that liquefied wood could be an effective binder for boron based preservative compounds; the possible influence of CCB containing liquefied wood on growth of wood decay fungi was investigated as well. It was stated, that CCB containing liquefied wood was less fungitoxic than the wood without $\mathrm{Cu}, \mathrm{Cr}$ and B. Small quantities of copper in liquefied wood even stimulated the growth of fungi. One reason for the observed fungicidal influence of liquefied wood without $\mathrm{Cu}, \mathrm{Cr}$ and $\mathrm{B}$ may originate in its very low $\mathrm{pH}$ value.

\section{REFERENCES}

European committee for standardisation. 2004. Wood preservatives - Test method for determining the protective effectiveness against wood destroying basidiomycetes - Determination of the toxic values, EN 113 2004. Brussels.

Asad, A.; Bell, R.W.; Dell, B.; Huang, L. 1997. Development of a boron buffered solution culture system for controlled studies of plant boron nutrition. Plant and Soil 188(1): 21-32.

Baysal, E.; Yalinkilic, M.A. 2005. A new boron impregnation technique of wood by vapor boron of boric acid to reduce leaching boron from wood. Wood science and technology 39(3): 187-198.

Budija, F.; Tavzes, Č.; Zupančič-Kralj, L.; Petrič, M. 2009. Self-crosslinking and film formation ability of liquefied black poplar. Bioresource Technology 100(13): 3316-3323.

Budija, F.; Zupančič-Kralj, L.; Petrič, M. 2010. Optimizacija utekočinjanja biomase z glicerolom in karakterizacija nastalih hlapnih produktov. (English title: Optimisation of biomass liquefaction with glycerol and characterisation of the formed volatile products). Les 62(5): 209-215.

D'Ulivo, A. 2004. Chemical vapor generation by tetrahydroborate(III) and other borane complexes in aqueous media. A critical discussion of fundamental processes and mechanisms involved in reagent decomposition and hydride formation. Spectrochimica Acta Part B-Atomic Spectroscopy 59(6): 793-825.

Demirbas, A. 2001. Biomass resource facilities and biomass conversion processing for fuels and chemicals. Energy Conversion and Management 42(11): 1357-1378.

Doh, G.H.; Lee, S.Y.; Kang, I.A.; Kong, Y.T. 2005. Thermal behavior of liquefied wood polymer composites (LWPC). Composite Structures 68(1): 103-108.

Helsen, L.; Van den Bulck, E. 2005. Review of disposal technologies for chromated copper arsenate (CCA) treated wood waste, with detailed analyses of thermochemical conversion processes. Environmental Pollution 134(2): 301-314. 
Helsen, L.; Hardy, A.; Van Bael, M.K.; Mullens, J. 2007. Tanalith E 3494 impregnated wood: Characterisation and thermal behaviour. Journal of Analytical and Applied Pyrolysis 78(1): 133-139.

Humar, M.; Šentjurc, M.; Amartey, S.A.; Pohleven, F. 2005. Influence of acidification of $\mathrm{CCB}(\mathrm{Cu} / \mathrm{Cr} / \mathrm{B})$ impregnated wood on fungal copper tolerance. Chemosphere 58(6): 743-749.

Humar, M.; Lesar, B. 2008. Fungicidal properties of individual components of copperethanolamine-based wood preservatives. International Biodeterioration \& Biodegradation 62(1): 4650 .

Humar, M.; Budija, F.; Hrastnik, D.; Lesar, B.; Petrič, M. 2011. Potentials of liquefied CCB treated waste wood for wood preservation. Drvna industrija 62(3): 213-218.

Kataoka, H.; Okamoto, Y.; Tsukahara, S., Fujiwara, T.; Ito, K. 2008. Separate vaporisation of boric acid and inorganic boron from tungsten sample cuvette-tungsten boat furnace followed by the detection of boron species by inductively coupled plasma mass spectrometry and atomic emission spectrometry (ICP-MS and ICP-AES). Analytica Chimica Acta 610(2): 179-185.

Kobayashi, M.; Tukamoto K.; Tomita, B. 2000. Application of Liquefied Wood to a New Resin System-Synthesis and Properties of Liquefied Wood/Epoxy Resins. Holzforschung 54(1): 93-97.

Krook, J.; Martensson, A.; Eklund, M. 2006. Sources of heavy metal contamination in Swedish wood waste used for combustion. Waste Management 26(2): 158-166.

Kunaver, M.; Medved, S.; Čuk, N.; Jasiukaityte, E.; Poljanšek, I.; Strnad, T. 2010. Application of liquefied wood as a new particle board adhesive system. Bioresource Technology 101(4): 1361-1368.

Kurimoto,Y.; Takeda, M.; Doi, S.; Tamura, Y.; Ono, H. 2001. Network structures and thermal properties of polyurethane films prepared from liquefied wood. Bioresource Technology 77(1): 33-40.

Landers, J.P.; Oda, R.P.; Schuchard, M.D. 1992. Separation of Boron-Complexed Diol Compounds Using High-Performance Capillary Electrophoresis. Anal. Chem 64(22): 2846-2851.

Lesar, B.; Budija, F.; Kralj, P.; Petrič, M.; Humar, M. 2012. Leaching of boron from wood impregnated with preservative solutions based acid and liquefied wood. European Journal of Wood and Wood Products 70(1-3): 365-367.

Lin, L.; Yao, Y.; Yoshioka, M.; Shiraishi, N. 1997. Molecular weights and molecular weight distributions of liquefied wood obtained by acid-catalyzed phenolysis. Journal of Applied Polymer Science 64(7): 351-357.

Lin, L.; Hse, C-Y. 2005. Liquefaction of CCA-treated wood and elimination of metals from the solvent by precipitation. Holzforschung 59(3): 285-288.

Maldas, DC.; Kamdem, DP. 1998. Surface tension and wettability of CCA-treated red maple. Wood and iber science 30(4): 368-373.

Obanda, D.N.; Shupe, T.F.; Barnes, M. 2008. Reducing leaching of boron-based wood preservatives -A review of research. Bioresource Technology 99(15): 7312-7322. 
Ohoa-Aua, H.G.; Roberts, S.M. 2006. Children Exposed to Playsets Treated with Chromated Copper Arsenate: A Review of Risk Assessment Approaches. In: Solo-Gabriele, H.; (Eds.) Townsend, T.; (Eds.) 2006. Environmental Impacts of Preservative-Treated Wood. Taylor \& Francis Group, Boca Raton.: 271-284.

Penn, S.G.; Hu, H.; Brown, P.H.; Lebrilla, . 1997. Direct Analysis of Sugar Alcohol Borate Complexes in Plant Extracts by Matrix-Assisted Laser Desorption/Ionization Fourier Transform Mass Spectrometry. Anal. Chem 69(13): 2471-2477.

Pohleven, F.; Malnarič, A.; Humar, M.; Tavzes, Č. 2001. Copper tolerance of various Antrodia vaillantii isolates, IRG/WP 01-10406. The international Research Group on Wood Protection, Stockholm.

Shapcott, D.; Khoury, K.; Demers, P.P.; Vobecky, J.; Vobecky, J. 1977. The measurement of volatile chromium in biological materials. Clinical Biochemistry 10(5): 178-180.

Shiraishi, N.; Yoshioka, M. 1998. Liquefaction of wood and its application, In: Paras P.; (Eds.) Plenum N.; (Eds.) Sci. Technol. Polym. Adv. Mater. Proc. Int. Conf. Front. Polym. Adv. Mater. $4^{\text {th }}$, Meeting Date 1997, New York, 699-707.

Shiraishi, N.; Hse, C.Y. 2000. Liquefaction of the used creosote-treated wood in the presence of phenol and its application to phenolic resin. Wood Ashesives 2000, Session 3B: Advances in Wood Ashesive Formulations 259-266.

Tsoul, C.T.; Yin, H.W.; Shiah, T.C. 2004. Reaction kinetics behavior of phenol formaldehyde wood adhesives by differential thermal analysis and its application. Taiwan Journal of Forest Science 19(4): 297-310.

Wazny, J.; Thornton, J. D. 1986. Comparative laboratory testing of strains of the dry rot fungus Serpula lacrymans. Holzforschung 40(6): 383-388.

Yamada, T.; Ono, H. 2001. Characterization of the products resulting from ethylene glycol liquefaction of cellulose. Journal of Wood Science 47(6): 458-464. 